\title{
Description of Common Clinical Presentations and Associated Short-Term Physical Therapy Clinical Outcomes in Patients With Neck Pain
}

\author{
Maggie E. Horn, DPT, MPH, PhD, ${ }^{a}$ Gerard P. Brennan, PT, PhD, ${ }^{b}$ \\ Steven Z. George, PT, PhD, ${ }^{c}$ Jeffrey S. Harman, PhD, ${ }^{d}$ Mark D. Bishop, PT, $\mathrm{PhD}^{\mathrm{e}}$
}

From the ${ }^{a}$ Department of Physical Therapy, Langston University, Langston, OK; ${ }^{b}$ Intermountain Healthcare, Salt Lake City, UT; ${ }^{c}$ Department of Physical Therapy, Brooks-PHHP Research Collaboration, ${ }^{d}$ Department of Health Services Research, Management and Policy, and ${ }^{e}$ Department of Physical Therapy, University of Florida, Gainesville, FL.

\begin{abstract}
Objective: To determine the effect of clinical presentations of neck pain on short-term physical therapy outcomes.

Design: Retrospective analysis of pair-matched groups from a clinical cohort.

Setting: Thirteen outpatient physical therapy clinics in 1 health care system.

Participants: Patients $(\mathrm{N}=1069)$ grouped by common clinical presentations of neck pain: nonspecific neck pain $(\mathrm{NSNP})$ with duration $<4$ weeks; NSNP with duration $>4$ weeks; neck pain with arm pain; neck pain with headache; and neck pain from whiplash.

Intervention: Conservative interventions provided by physical therapists.

Main Outcome Measures: Neck Disability Index (NDI) and numerical pain rating scale (NPRS) recorded at the initial and last visits. The main outcome of interest was achieving recovery status on the NDI. Changes in NDI and NPRS were compared between clinical presentation groups. Results: Compared with patients presenting with NSNP $>4$ weeks, patients with NSNP $<4$ weeks had increased odds of achieving recovery status on the NDI $(P<.0001)$ and demonstrated the greatest changes in clinical outcomes of pain $(P \leq .0001)$ and disability $(P \leq .0001)$. Patients with neck pain and arm pain demonstrated an increased odds of achieving recovery status on the NDI $(P=.04)$ compared with patients presenting with NSNP $>4$ weeks.

Conclusions: Treating patients with NSNP within $<4$ weeks of onset of symptoms may lead to improved clinical outcomes from physical therapy compared with other common clinical presentations.
\end{abstract}

Archives of Physical Medicine and Rehabilitation 2015;96:1756-62

(C) 2015 by the American Congress of Rehabilitation Medicine

Neck pain is the second most common musculoskeletal disorder in population surveys and is associated with high injury and disability claims. ${ }^{1,2}$ It is generally accepted that neck pain has a favorable course of care, ${ }^{3}$ but there is variation in short-term outcomes in patients with neck pain. ${ }^{3,4}$

Certain factors are known to be prognostic for the course of neck pain, and several interventions, including those provided by physical therapists, are likely to produce a favorable outcome. ${ }^{5-9}$ Approximately $35 \%$ of persons with neck pain reported being seen by a physical therapist, the most frequently visited provider, ${ }^{10}$ and evidence suggests that physical therapy can be an

Disclosures: none. effective secondary prevention strategy for neck pain. ${ }^{11}$ In recent years, organized efforts have been made to improve clinical outcomes and standardize physical therapy treatment, including using classification system approaches. Fritz and Brennan ${ }^{12}$ supported that subgrouping patients with neck pain and providing interventions matched to the patient classification improves shortterm outcomes of pain and disability from physical therapy, but this approach has not been validated nor have other classification systems published in the literature been validated. ${ }^{13,14}$

Therefore in this study, rather than introduce a new classification system, we wished to pragmatically examine a large cohort of patients with common clinical presentations of neck pain. The purposes of this study were to describe the demographics and 
clinical characteristics of patients receiving outpatient physical therapy for neck pain with 5 common clinical presentations, determine which clinical presentation groups experienced the greatest changes in clinical outcomes of pain and disability during an episode of care, and ultimately determine whether clinical presentation increases the odds of recovery from an episode of neck pain.

\section{Methods}

\section{Participants}

Patients included in this study received physical therapy intervention for the primary complaint of neck pain between January 1, 2008, and December 31, 2011, from 13 outpatient physical therapy clinics located in Salt Lake City, Utah and surrounding regions. A retrospective analysis of data was performed. Inclusion criteria for these analyses were as follows: (1) nonsurgical patient; (2) Neck Disability Index (NDI) score $\geq 10$ and numerical pain rating scale (NPRS) $\geq 2$ at initial evaluation; (3) $\geq 2$ visits; and (4) duration of treatment (DOT) between 2 and 180 days. The criteria were implemented to permit the evaluation of clinical outcomes. $^{12,15}$ that exceed measurement error. ${ }^{16,17}$ The study protocol was approved by the Institutional Review Board of Intermountain Healthcare.

\section{Database}

Data were extracted for this study from the Rehabilitation Outcomes Management System and the AS-400 financial databases. These databases contain demographic, clinical outcomes, and billing data that are maintained by Intermountain Healthcare, a private, nonprofit integrated health care system.

\section{Outcome measures}

At each visit, patients completed a condition-specific disability questionnaire, the NDI, and a pain rating scale, the NPRS. The NDI is a condition-specific outcome measure composed of 10 items; each item is scored from 0 to 5 . The total score is expressed as a percentage and is reflective of a level of disability related to neck pain where high percentages are related to higher disability. The NDI is a commonly used outcome measure for people with neck pain and has been found to be reliable and valid in the neck pain population. ${ }^{18-22}$ The NPRS is an 11-point scale, anchored with 0 rated as "no pain" and 10 rated as "worst pain" imaginable. Patients are asked to rate their current pain using this scale. The NPRS exhibits fair to moderate test-retest reliability in patients with mechanical neck pain and shows adequate responsiveness in this patient population. ${ }^{16,23}$ The minimal clinically important difference for the NDI has been reported as a 19-percentage-point change (9.5 raw score), and the minimal clinically important

\begin{tabular}{|l|}
\hline List of abbreviations: \\
CI confidence interval \\
CPT Current Procedural Terminology \\
DOT duration of treatment \\
NDI Neck Disability Index \\
NSNP nonspecific neck pain \\
NPRS numerical pain rating scale \\
\hline
\end{tabular}

difference for the NPRS has been reported as a 1.3-point change in this population. ${ }^{23}$

\section{Clinical variables}

Demographic and process variables were included in the clinical outcomes database including age, sex, number of physical therapy visits, and DOT. Records from the Rehabilitation Outcomes Management System database were linked to the AS-400 database using an enterprise master patient index number. The billing database contains Current Procedural Terminology (CPT) codes billed for physical therapy services during an episode of care. These codes are billed by the physical therapist and recorded in the AS-400 database at each visit. The billed CPT codes are reflective of the type of intervention provided by the physical therapist at each visit. Physical therapists contributing data to this analysis did not receive additional training on CPT coding for purposes of this study.

\section{Clinical presentation}

At initial evaluation, patients seeking care for neck pain were categorized into 1 of 5 clinical presentation groups by a physical therapist. These groups were created as broad categories to describe common clinical presentations of patients with neck pain by the rehabilitation department at Intermountain Healthcare in 2002 to evaluate clinical outcomes. Studies support that the clinical presentation of neck pain with arm pain, ${ }^{24,25}$ neck pain with headache, ${ }^{26}$ and neck pain from whiplash ${ }^{27}$ differ in their clinical course compared to patients with acute, subacute, or chronic nonspecific neck pain (NSNP) ${ }^{28}$ This strategy has been implemented at Intermountain Healthcare since 2002, and there is a $94.5 \%$ adherence rate in collecting these clinical data by physical therapists. ${ }^{29}$ Physical therapists were oriented to using this categorization method at clinical training sessions at the time of hiring and used the criteria in table 1 for categorizing patients. Reliability of the categorization method by the physical therapists was examined by 1 author in this study by reviewing 100 randomly selected charts. The interrater reliability was found to be acceptable $\left(\mathrm{ICC}_{2,2}=.91, P<.001\right)$.

Patients were categorized into 1 of the following groups for comparison: (1) NSNP with duration $<4$ weeks (NSNP $<4$ wk); (2) NSNP with duration $>4$ weeks (NSNP $>4 \mathrm{wk}$ ); (3) neck pain with arm pain; (4) neck pain with headache; and (5) neck pain from whiplash. The determination of the clinical presentations of headache, neck pain with arm pain, and whiplash were made based on patient self-report of symptoms related to the appropriate clinical presentation and objective tests found in table 1. Although some patients may present with both temporal and clinical presentations consistent with multiple groups, by default, patients are categorized by their clinical presentation in the following hierarchy: whiplash, neck pain with arm pain, or neck pain with headache, and patients with NSNP are categorized by temporality of symptoms (duration $<4 \mathrm{wk}$ or $>4 \mathrm{wk}$ ). Criteria for membership in clinical presentation groups can be found in table 1 .

\section{Intervention}

A variable, "\% active treatment," was calculated from CPT codes to reflect the type of physical therapy intervention received in lieu of specific data related to treatment. The algorithm used to calculate this variable has been previously published as a method 
Table 1 Criteria for membership in clinical presentation groups

\begin{tabular}{|c|c|}
\hline Group & Criteria for Group Membership \\
\hline NSNP $<4 w k$ & $\begin{array}{l}\text { - Recent onset of symptoms }(<4 \mathrm{wk})^{*} \\
\text { - No symptoms distal to the shoulder } \\
\text { - Restricted neck AROM } \\
\text { - No signs of nerve root compression }\end{array}$ \\
\hline NSNP $>4 w k$ & $\begin{array}{l}\text { - Longer symptom duration }(>4 \mathrm{wk})^{*} \\
\text { - No peripheralization/centralization with AROM } \\
\text { - No signs of nerve root compression }\end{array}$ \\
\hline $\begin{array}{l}\text { Neck pain with } \\
\text { arm pain }\end{array}$ & $\begin{array}{l}\text { - Peripheralization/centralization with } \text { AROM }^{\dagger} \\
\text { - Symptoms distal to shoulder } \\
\text { - Signs of nerve root compression } \\
\text { - Positive distraction, Spurling's, or upper limb } \\
\text { tension testing }\end{array}$ \\
\hline $\begin{array}{l}\text { Neck pain with } \\
\text { headache }\end{array}$ & $\begin{array}{l}\text { - Unilateral-dominant headache with neck pain } \\
\text { - Headache associated with neck movements or } \\
\text { positions* } \\
\text { - Tenderness in upper } 3 \text { cervical joints } \\
\text { - No migraine history or symptoms of migraine }\end{array}$ \\
\hline $\begin{array}{l}\text { Neck pain from } \\
\text { whiplash }\end{array}$ & $\begin{array}{l}\text { - Recent onset of symptoms }(<2 \mathrm{wk}) \text { related to } \\
\text { a traumatic onset }(\mathrm{eg}, \mathrm{MVC})^{*}\end{array}$ \\
\hline
\end{tabular}

Abbreviations: AROM, active range of motion; MVC, motor vehicle collision.

* Patients must present with this key finding to be categorized in the clinical presentation group.

$\dagger$ Patients may present with any one of these findings to be categorized in this group.

to describe the type of treatment received when using a database to analyze rehabilitation outcomes and to reflect adherence to clinical practice guidelines. ${ }^{15,30} \mathrm{CPT}$ codes billed were categorized as "active + manual therapy," "passive," or "allowed." Codes classified as active + manual therapy indicated procedures consistent with clinical guidelines for neck pain and represent interventions such as stretching and strengthening exercises, centralization exercises, upper quarter and nerve mobilization procedures, and spinal manipulation and mobilization (97110, 97350, 97535, 97112, 97150, 97140). ${ }^{14}$ The codes classified as passive indicated procedures that were primarily modalities or mechanical traction $(97035,97010,97032$, 97012, 97124, 97024, 97026). Allowed codes represent procedures that could not be adequately categorized to reflect adherence to guidelines and were not included in calculations. The number of active + manual therapy codes and passive codes billed at each visit was recorded. The proportion of active + manual therapy codes to overall codes was calculated and then expressed as a percentage, using the following formula:

$$
\begin{aligned}
\% \text { Active Care } & =([\text { No. of Active }+ \text { Manual Therapy Codes }] \\
& /[\text { No. of Active }+ \text { Manual Therapy Codes } \\
& + \text { No. of Passive Codes }]) \times 100
\end{aligned}
$$

\section{Outcomes}

During an episode of care, patients completed the NDI and NPRS. Scores from the initial visit and final visit were recorded. Change in NPRS and change in NDI scores were calculated for each patient in the sample. This was calculated by subtracting the score at the last visit from the initial score for the NPRS and NDI. The NDI was further dichotomized to reflect disability status at the last visit. Patients reporting an NDI percentage score of $8 \%$ or less were categorized as "recovered," and patients reporting a score of 9\% or greater were further categorized as "not fully recovered." Vernon, ${ }^{31}$ the developer of the original NDI, cites that a score of $8 \%$ points (4 raw points) on the NDI is reflective of no disability related to neck pain. ${ }^{31}$ Sterling and Kenardy ${ }^{32}$ established $8 \%$ points on the NDI as a cutoff to determine if a patient has recovered from an episode of neck pain, and this cutoff is commonly used in clinical practice and research.

An episode of physical therapy was defined as the physical therapy treatment provided from the initial evaluation to the date of the last visit for a patient. For each episode of care included in the sample, the DOT was defined as the number of days between the initial evaluation and the last visit. The last visit was defined as the last visit recorded for a uniquely identified episode of care. The DOT also reflects the follow-up time for the outcome measures. The number of visits was defined as the number of visits that patients attended during an episode of care.

\section{Data analysis}

Data analysis was performed using SPSS statistical software (version $21.0^{\mathrm{a}}$ ). The significance level for all analyses was set at .05 .

Our main outcome of interest in this study was "recovery" from an episode of neck pain. Preliminary analyses revealed a significant difference in the variable "\% active treatment" (a proxy measure for physical therapy intervention) between recovery groups ( $t=2.58, P=.01)$. Therefore, to reduce the bias associated with potential differences in the physical therapy intervention provided between groups, pair-matched sampling was performed. Pair matching was performed using exact matches between recovery groups on the continuous variable of $\%$ active treatment using the method described by Cochran ${ }^{33}$ and Rubin. ${ }^{34}$ This method reduces the bias associated with the effect of treatment and increases the precision of estimates. ${ }^{34}$ This method was selected over propensity score matching because of the desire to minimize the bias associated with the effect treatment rather than adjust for multiple baseline characteristics. ${ }^{35}$ After pair matching was performed and incomplete observations were removed, 1069 episodes of care were included in the final analysis. Derivation of the final sample for analysis can be found in figure 1 .

Descriptive statistics were calculated to characterize the clinical presentation groups in this sample. Means and SDs were reported for continuous variables, and percentages were reported for categorical variables. Baseline patient characteristics, clinical outcomes, and physical therapy utilization were compared among clinical presentation groups using chi-square analyses for categorical variables and 1-way analyses of variance for continuous variables.

To determine which groups experienced the greatest changes in clinical outcomes during an episode of care, separate analysis of covariance models were performed to examine the effect of clinical presentation group on the dependent variables of change in NDI score and change in NPRS during an episode of physical therapy. Covariates for both models included sex, age, DOT, and visits. To determine the difference in the odds of achieving "recovery" on the NDI, binary logistic regression was performed where clinical presentation group was the main predictor of interest and the covariates in the model included DOT, number of visits, sex, and admission NDI score. Model selection for all analyses was performed using an initial set of potentially confounding variables based on previous literature on prognostic factors ${ }^{14,36}$ and conceptually driven variables. ${ }^{37}$ Variables were 


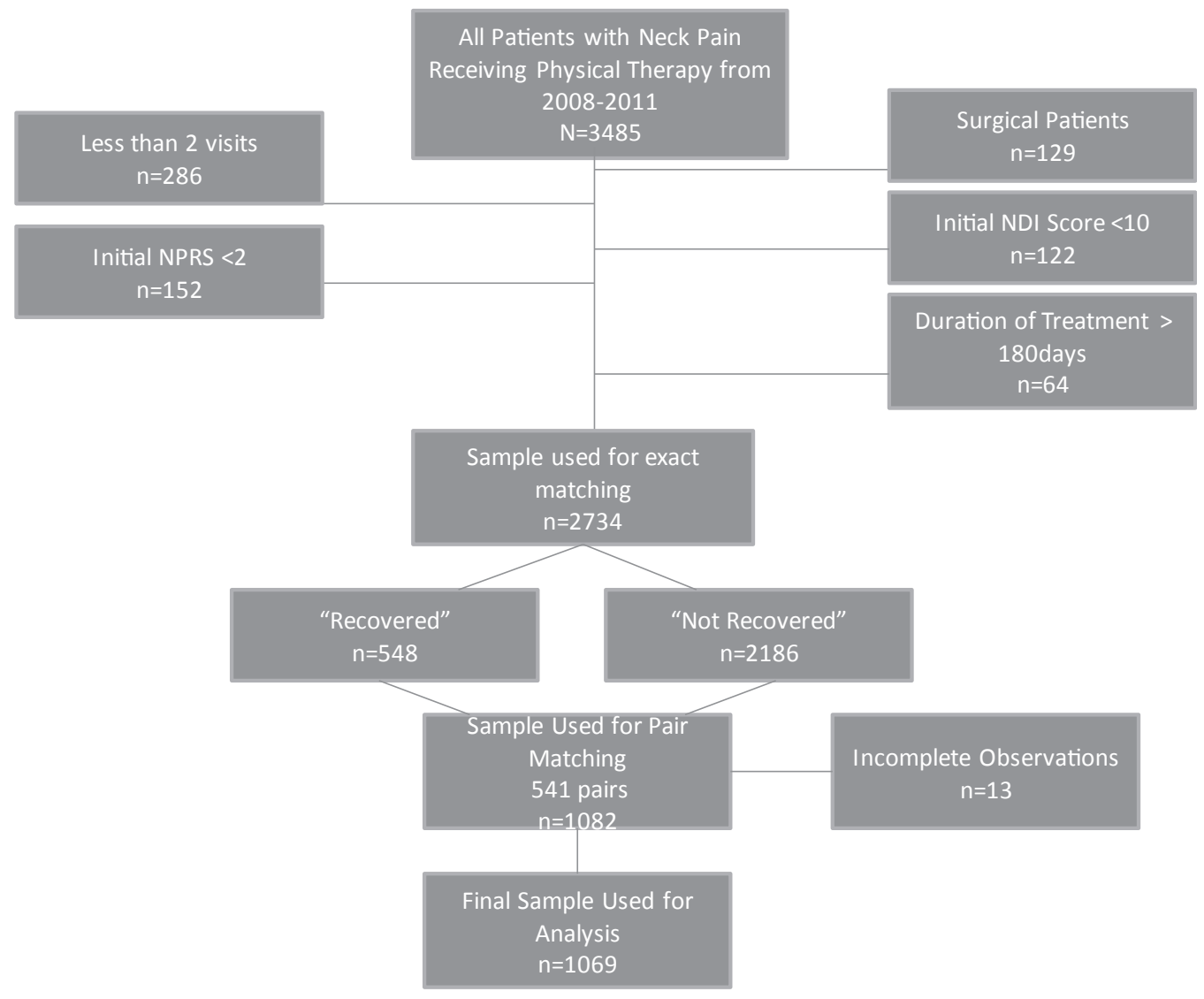

Fig 1 Derivation of sample used in final analysis.

removed if they did not improve model fit as measured by the explained variance in the exploratory models.

\section{Results}

The NSNP $>4$ weeks group comprised $38.7 \%$ of the total sample followed by the neck pain with arm pain group (22\%), NSNP $<4$ weeks neck pain $(17.3 \%)$, headache with neck pain $(12.8 \%)$, and whiplash $(7.8 \%)$.

Patients in the whiplash group were the youngest with a mean age \pm SD of $41.82 \pm 16.02$ years, and the oldest group were patients in the NSNP $>4$ weeks group aged $53.33 \pm 17.14$ years. Most of the sample in each clinical group were women with percentages ranging from $56.5 \%$ to $79.9 \%$, with the highest percentage of women in the headache group and the lowest percentage of women in the neck pain with arm pain group.

The mean DOT varied between approximately 24 and 40 days. Patients with NSNP $<4$ weeks had the shortest DOT \pm SD $(23.64 \pm 21.93 \mathrm{~d})$, and the whiplash group had the longest DOT $(39.81 \pm 31.83 \mathrm{~d})$. The mean $\pm \mathrm{SD}$ number of visits ranged from $5.09 \pm 3.21$ for patients with NSNP $<4$ weeks to $7.01 \pm 4.34$ for patients in the whiplash group (table 2).

There was a significant effect of clinical presentation on change in disability $\left(\mathrm{F}_{4,1053}=13.577, P \leq .0001\right)$, where the greatest change in NDI was demonstrated by the patients in the NSNP $<4$ weeks group (20.25 points; 95\% confidence interval [CI], 18.07-22.44), and the least amount of change was reported in the NSNP $>4$ weeks group (10.96 points; $95 \% \mathrm{CI}$, 9.46-12.46). There was also a significant effect of clinical presentation on change in pain $\left(\mathrm{F}_{4,1051}=8.64, P \leq .0001\right)$, where again the greatest change was demonstrated by the patients in the NSNP $<4$ weeks group (3.24 points; $95 \%$ CI, 2.87-3.61), and the least amount of change was reported in the NSNP $>4$ weeks group (2.01 points; 95\% CI, 1.75-2.26) (table 3).

When compared with the NSNP $>4$ weeks group, patients in the NSNP $<4$ weeks group demonstrated 2.17 times $(P<.0001$; 95\% CI, 1.44-3.27) the odds of achieving recovery status on the NDI, and patients in the neck pain with arm pain group $(P=.04$; 95\% CI,1.01-2.07) demonstrated 1.44 times the odds of achieving recovery status (table 4).

\section{Discussion}

The purposes of this study were to describe the clinical characteristics and compare clinical outcomes in patients with 5 common clinical presentations receiving outpatient physical therapy services for neck pain. The findings of this study support that patients with 5 common clinical presentations of neck pain vary in their clinical outcomes related to physical therapy intervention. Comparing patients with common clinical presentations of neck pain revealed that patients with NSNP $<4$ weeks demonstrated the greatest improvements in pain (NPRS) and disability (NDI), and demonstrated increased odds of achieving recovery on the NDI. Conversely, patients with NSNP $>4$ weeks had the poorest 
Table 2 Description of common clinical presentation groups

\begin{tabular}{|c|c|c|c|c|c|c|}
\hline \multirow[b]{2}{*}{ Variable } & \multicolumn{6}{|c|}{ Clinical Presentation } \\
\hline & $\begin{array}{l}\text { NSNP }<4 \text { wk } \\
(n=187)\end{array}$ & $\begin{array}{l}\text { NSNP }>4 w k \\
(n=419)\end{array}$ & $\begin{array}{l}\text { Neck Pain With } \\
\text { Arm Pain }(n=239)\end{array}$ & $\begin{array}{l}\text { Neck Pain With } \\
\text { Headache }(n=139)\end{array}$ & $\begin{array}{l}\text { Neck Pain From } \\
\text { Whiplash }(n=85)\end{array}$ & $P^{*}$ \\
\hline Age $(y)$ & $45.33 \pm 15.64$ & $53.33 \pm 17.14$ & $51.57 \pm 12.23$ & $43.81 \pm 15.98$ & $41.82 \pm 16.02$ & $<.001$ \\
\hline Women $(\%)$ & 62.6 & 66.3 & 56.5 & 79.9 & 76.65 & $<.001$ \\
\hline DOT (d) & $23.64 \pm 21.93$ & $32.29 \pm 25.70$ & $30.24 \pm 25.07$ & $32.58 \pm 25.02$ & $39.81 \pm 31.83$ & $<.001$ \\
\hline Visits & $5.09 \pm 3.21$ & $5.36 \pm 2.75$ & $6.00 \pm 3.98$ & $5.54 \pm 3.54$ & $7.01 \pm 4.34$ & $<.001$ \\
\hline Initial NDI & $37.04 \pm 16.75$ & $31.01 \pm 14.80$ & $32.41 \pm 15.37$ & $31.79 \pm 15.37$ & $35.33 \pm 16.39$ & $<.001$ \\
\hline Final NDI & $16.37 \pm 16.63$ & $19.61 \pm 17.11$ & $17.91 \pm 16.94$ & $18.32 \pm 16.35$ & $17.35 \pm 15.74$ & .25 \\
\hline Change NDI & $20.67 \pm 16.66$ & $11.41 \pm 14.15$ & $14.49 \pm 14.57$ & $13.47 \pm 13.41$ & $17.98 \pm 16.20$ & $<.001$ \\
\hline Initial NPRS & $5.66 \pm 2.23$ & $4.95 \pm 2.09$ & $5.41 \pm 2.24$ & $5.06 \pm 2.34$ & $5.26 \pm 2.01$ & .002 \\
\hline Final NPRS & $2.36 \pm 2.42$ & $2.92 \pm 2.36$ & $2.49 \pm 2.31$ & $2.83 \pm 2.29$ & $2.55 \pm 2.31$ & .04 \\
\hline Change NPRS & $3.29 \pm 2.60$ & $2.03 \pm 2.36$ & $2.92 \pm 2.62$ & $2.23 \pm 2.66$ & $2.70 \pm 2.41$ & $<.001$ \\
\hline $\begin{array}{l}\% \text { Achieved } \\
\text { recovery on NDI }\end{array}$ & 54.0 & 47.3 & 53.1 & 48.9 & 48.2 & .47 \\
\hline$\%$ Change in NDI & $56.48 \pm 56.95$ & $37.29 \pm 33.89$ & $46.19 \pm 41.70$ & $43.95 \pm 38.28$ & $49.19 \pm 45.25$ & $<.001$ \\
\hline$\%$ Change in NPRS & $58.82 \pm 36.61$ & $39.12 \pm 49.89$ & $51.87 \pm 41.99$ & $37.28 \pm 57.02$ & $51.65 \pm 40.19$ & $<.001$ \\
\hline
\end{tabular}

outcomes across all metrics. Patients with the clinical presentation of whiplash behave similarly to patients with a duration of symptoms $<4$ weeks when looking at clinical outcomes, but have a longer DOT and a greater number of visits during an episode of physical therapy, which is consistent with the literature. ${ }^{38}$ Patients in the neck pain with arm pain and headache groups varied in their clinical outcomes, consistent with the literature on general prognostic factors related to these presentations. ${ }^{25,39}$

Moreover, our sample is consistent with the demographics of patients with neck pain, with patients being primarily women and having a mean age in the mid-40s. ${ }^{40}$ The number of physical therapy visits and DOT reported in our sample was also consistent with the literature for patients with musculoskeletal conditions. ${ }^{29}$ Short-term disability and pain outcomes ${ }^{31}$ reflect values that are consistent with patients receiving conservative treatment. ${ }^{31}$

Although our findings are consistent with the literature on the general prognosis of neck pain, this study adds valuable information on short-term outcomes from physical therapy. Across all metrics, patients with a duration of symptoms $<4$ weeks have the greatest improvements and have increased odds of recovery compared with other clinical presentations. Intuitively, one would suspect this could be attributed to natural recovery. Farrar ${ }^{41}$ and Vernon $^{42}$ and colleagues found that change scores in pain and disability attributable to natural recovery are not generally greater than $15 \%$ to $20 \%$. In this study, the NSNP $<4$ weeks group demonstrated a $56.48 \%$ improvement in disability and a $58.82 \%$ improvement in pain, well surpassing estimates of natural recovery. The finding of improved outcomes with early care has been supported not only in the neck pain literature ${ }^{28,43}$ but also in the low back pain literature. ${ }^{44}$ These convergent findings suggest consideration of practice or policy level changes in the future if more efficient management of spine pain is to be realized.

\section{Study limitations}

There are limitations in the current study. The follow-up time in this study was relatively short, ranging from 24 to 40 days in each group, and there were no long-term follow-up data available on outcome measures. Although this is a limitation, it is not inconsistent with studies examining physical therapy short-term outcomes. ${ }^{17}$ Patients were categorized based on common clinical presentations, and within each group there is the potential for variability in the type of patient included in that grouping. In the temporally based groups, patients in each group may vary with the actual duration of their symptoms, which may affect outcomes. In the symptom-based groups, the literature supports differential expected outcomes regarding patients with graded whiplash diagnoses, ${ }^{45}$ but data on whiplash grading was not available for use

Table 3 Adjusted mean difference in clinical outcomes between clinical presentation groups

\begin{tabular}{llllll}
\hline Outcomes & NSNP $<4 w k$ & NSNP $>4 w k$ & Neck Pain With & Neck Pain With & Neck Pain From \\
$(n=187)$ & Arm Pain $(n=239)$ & Headache $(n=139)$ & Whiplash $(n=85)$ \\
\hline $\begin{array}{l}\text { Change in } \\
\text { pain } \\
\text { (NPRS) }\end{array}$ & $3.24(2.87-3.61)$ & $2.01(1.75-2.26)$ & $2.82(2.50-3.14)$ & $2.28(1.75-2.81)$ & $2.89(2.26-3.53)$ \\
$\begin{array}{l}\text { Change in } \\
\text { disability } \\
\text { (NDI) }\end{array}$ & $20.25(18.07-22.44)$ & $10.96(9.46-12.46)$ & $13.90(12.03-15.77)$ & $14.04(11.01-17.07)$ & $19.62(15.92-23.31)$ \\
\hline
\end{tabular}

NOTE. Values are adjusted means (95\% CIs). Covariates included in models: (1) change in NDI score: sex, age, DOT, visits; (2) change in NPRS score: sex, age, DOT, visits. 
Table 4 Odds of achieving recovery status on NDI

\begin{tabular}{|c|c|c|c|c|}
\hline \multirow[b]{2}{*}{ Variable } & \multirow[b]{2}{*}{$\mathrm{aOR}$} & \multirow[b]{2}{*}{$P$} & \multicolumn{2}{|c|}{$95 \%$ CI for aOR } \\
\hline & & & Lower & Upper \\
\hline \multicolumn{5}{|l|}{ Clinical presentation } \\
\hline NSNP $>4 w k$ & Ref & NA & NA & NA \\
\hline NSNP $<4 w k$ & 2.17 & $<.0001$ & 1.44 & 3.27 \\
\hline Neck pain with arm pain & 1.44 & .04 & 1.01 & 2.07 \\
\hline Neck pain with headache & 1.15 & .52 & 0.75 & 1.77 \\
\hline Neck pain from whiplash & 1.35 & .26 & 0.79 & 2.31 \\
\hline DOT (d) & 0.99 & .35 & 0.99 & 1.00 \\
\hline Visits & 1.05 & .08 & 0.99 & 1.10 \\
\hline \multicolumn{5}{|l|}{ Sex } \\
\hline Male & Ref & NA & NA & NA \\
\hline Female & 1.07 & .61 & 0.81 & 1.43 \\
\hline Age & 1.00 & .75 & 0.99 & 1.01 \\
\hline Admission NDI score & 0.93 & $<.001$ & 0.92 & 0.94 \\
\hline
\end{tabular}

in this study. Additionally, there is a great deal of variability in patients presenting with neck pain and associated arm pain, where symptoms can be mild to severe with complaints of nerve root compression. We fully acknowledge that heterogeneity exists within the groups, but see it rather as a strength of the study. This heterogeneity may be more reflective of general practice, where clinicians may not have access to evidence on whiplash grading or diagnostic techniques to assess the severity of neck pain and arm pain.

\section{Conclusions}

Understanding factors that can influence the clinical outcomes from physical therapy in patients with neck pain is paramount to decrease the burden neck pain places on the individual and the health care system, and to inform rehabilitation professionals. The current study supports that there is variation in outcomes from conservative physical therapy intervention between clinical presentations, but receiving physical therapy intervention for NSNP when the duration of symptoms is $<4$ weeks can lead to improved clinical outcomes. The clinical implications of these findings supports that patients should seek timely care during an episode of neck pain to improve short-term clinical outcomes.

\section{Supplier}

a. SPSS statistical software (version 21.0); IBM Corp.

\section{Keywords}

Disability evaluation; Neck pain; Outcome assessment (health care); Rehabilitation

\section{Corresponding author}

Maggie E. Horn, DPT, MPH, PhD, PO Box 1500, Langston, OK 73050. E-mail address: mehorn@langston.edu.

\section{References}

1. Ferrari R, Russell AS. Regional musculoskeletal conditions: neck pain. Best Pract Res Clin Rheumatol 2003;17:57-70.

2. McBeth J, Macfarlane GJ, Benjamin S, Morris S, Silman AJ. The association between tender points, psychological distress, and adverse childhood experiences: a community-based study. Arthritis Rheum 1999;42:1397-404.

3. Di Fabio RP, Boissonnault W. Physical therapy and health-related outcomes for patients with common orthopaedic diagnoses. J Orthop Sports Phys Ther 1998;27:219-30.

4. Bot SD, van der Waal JM, Terwee CB, et al. Predictors of outcome in neck and shoulder symptoms - a cohort study in general practice. Spine 2005;30:E459-70.

5. Showalter C, O'Hearn M. Cervical and thoracic mobilization versus manipulation for mechanical neck pain. Letter. J Orthop Sports Phys Ther 2012;42:385-6. author reply 386-92.

6. Puentedura EJ, Cleland JA, Landers MR, Mintken PE, Louw A, Fernandez-de-Las-Penas C. Development of a clinical prediction rule to identify patients with neck pain likely to benefit from thrust joint manipulation to the cervical spine. J Orthop Sports Phys Ther 2012; 42:577-92.

7. Cleland JA, Mintken PE, Carpenter K, et al. Examination of a clinical prediction rule to identify patients with neck pain likely to benefit from thoracic spine thrust manipulation and a general cervical range of motion exercise: multi-center randomized clinical trial. Phys Ther 2010;90:1239-50.

8. Cleland JA, Childs JD, Fritz JM, Whitman JM, Eberhart SL. Development of a clinical prediction rule for guiding treatment of a subgroup of patients with neck pain: use of thoracic spine manipulation, exercise, and patient education. Phys Ther 2007;87:9-23.

9. Childs JD, Cleland JA. Development and application of clinical prediction rules to improve decision making in physical therapist practice. Phys Ther 2006;86:122-31.

10. Goode AP, Freburger J, Carey T. Prevalence, practice patterns, and evidence for chronic neck pain. Arthritis Care Res 2010;62:1594-601.

11. Linton SJ, van Tulder MW. Preventive interventions for back and neck pain problems: what is the evidence? Spine 2001;26:778-87.

12. Fritz JM, Brennan GP. Preliminary examination of a proposed treatment-based classification system for patients receiving physical therapy interventions for neck pain. Phys Ther 2007;87:513-24.

13. Wang WT, Olson SL, Campbell AH, Hanten WP, Gleeson PB. Effectiveness of physical therapy for patients with neck pain: an individualized approach using a clinical decision-making algorithm. Am J Phys Med Rehabil 2003;82:203-18. quiz 219-21.

14. Childs JD, Cleland JA, Elliott JM, et al. Neck pain: clinical practice guidelines linked to the International Classification of Functioning, Disability, and Health from the Orthopedic Section of the American Physical Therapy Association. J Orthop Sports Phys Ther 2008;38:A134.

15. Fritz JM, Cleland JA, Brennan GP. Does adherence to the guideline recommendation for active treatments improve the quality of care for patients with acute low back pain delivered by physical therapists? Med Care 2007;45:973-80.

16. Childs JD, Piva SR, Fritz JM. Responsiveness of the numeric pain rating scale in patients with low back pain. Spine 2005;30:1331-4.

17. MacDermid JC, Walton DM, Avery S, et al. Measurement properties of the Neck Disability Index: a systematic review. J Orthop Sports Phys Ther 2009;39:400-17.

18. Pietrobon R, Coeytaux RR, Carey TS, Richardson WJ, DeVellis RF. Standard scales for measurement of functional outcome for cervical pain or dysfunction: a systematic review. Spine 2002;27:515-22.

19. Hains F, Waalen J, Mior S. Psychometric properties of the Neck Disability Index. J Manipulative Physiol Ther 1998;21:75-80.

20. Riddle DL, Stratford PW. Use of generic versus region-specific functional status measures on patients with cervical spine disorders. Phys Ther 1998;78:951-63. 
21. Westaway MD, Stratford PW, Binkley JM. The Patient-Specific Functional Scale: validation of its use in persons with neck dysfunction. J Orthop Sports Phys Ther 1998;27:331-8.

22. Wheeler AH, Goolkasian P, Baird AC, Darden BV II. Development of the Neck Pain and Disability Scale. Item analysis, face, and criterionrelated validity. Spine 1999;24:1290-4.

23. Cleland JA, Childs JD, Whitman JM. Psychometric properties of the Neck Disability Index and numeric pain rating scale in patients with mechanical neck pain. Arch Phys Med Rehabil 2008;89:69-74.

24. Honet JC, Puri K. Cervical radiculitis: treatment and results in 82 patients. Arch Phys Med Rehabil 1976;57:12-6.

25. Radhakrishnan K, Litchy WJ, O'Fallon WM, Kurland LT. Epidemiology of cervical radiculopathy. A population-based study from Rochester, Minnesota, 1976 through 1990. Brain 1994;117(Pt 2): 325-35.

26. Hoving JL, de Vet HC, Twisk JW, et al. Prognostic factors for neck pain in general practice. Pain 2004;110:639-45.

27. Bunketorp L, Nordholm L, Carlsson J. A descriptive analysis of disorders in patients 17 years following motor vehicle accidents. Eur Spine J 2002;11:227-34.

28. Borghouts JA, Koes BW, Bouter LM. The clinical course and prognostic factors of non-specific neck pain: a systematic review. Pain 1998;77:1-13

29. Fritz JM, Hunter SJ, Tracy DM, Brennan GP. Utilization and clinical outcomes of outpatient physical therapy for Medicare beneficiaries with musculoskeletal conditions. Phys Ther 2011;91:330-45.

30. Horn ME, Brennan GP, George SZ, Harman JS, Bishop MD. Clinical outcomes, utilization, and charges in persons with neck pain receiving guideline adherent physical therapy. Eval Health Prof. 2015 Apr 27. [Epub ahead of print]

31. Vernon H. The Neck Disability Index: state-of-the-art, 1991-2008. J Manipulative Physiol Ther 2008;31:491-502.

32. Sterling M, Kenardy J. The relationship between sensory and sympathetic nervous system changes and posttraumatic stress reaction following whiplash injury-a prospective study. J Psychosom Res 2006;60:387-93

33. Cochran WG. Matching in analytical studies. Am J Public Health 1953;43:684-91.
34. Rubin DB. Matching to remove bias in observational studies. Biometrics 1973;29:159-83.

35. Austin PC. An introduction to propensity score methods for reducing the effects of confounding in observational studies. Multivariate Behav Res 2011;46:399-424.

36. Carroll LJ, Hogg-Johnson S, van der Velde G, et al. Course and prognostic factors for neck pain in the general population: results of the Bone and Joint Decade 2000-2010 Task Force on Neck Pain and Its Associated Disorders. Spine 2008;33(4 Suppl):S75-82.

37. Donabedian A. Methods for deriving criteria for assessing the quality of medical care. Med Care Rev 1980;37:653-98.

38. Carroll LJ, Holm LW, Hogg-Johnson S, et al. Course and prognostic factors for neck pain in whiplash-associated disorders (WAD): results of the Bone and Joint Decade 2000-2010 Task Force on Neck Pain and Its Associated Disorders. Spine 2008;33(4 Suppl):S83-92.

39. Cote P, van der Velde G, Cassidy JD, et al. The burden and determinants of neck pain in workers: results of the Bone and Joint Decade 2000-2010 Task Force on Neck Pain and Its Associated Disorders. Spine 2008;33(4 Suppl):S60-74.

40. Cote P, Cassidy JD, Carroll LJ, Kristman V. The annual incidence and course of neck pain in the general population: a population-based cohort study. Pain 2004;112:267-73.

41. Farrar JT, Young JP Jr, LaMoreaux L, Werth JL, Poole RM. Clinical importance of changes in chronic pain intensity measured on an 11point numerical pain rating scale. Pain 2001;94:149-58.

42. Vernon H, Humphreys BK, Hagino C. The outcome of control groups in clinical trials of conservative treatments for chronic mechanical neck pain: a systematic review. BMC Musculoskelet Disord 2006;7:58.

43. Leaver AM, Maher CG, McAuley JH, Jull G, Latimer J, Refshauge KM. People seeking treatment for a new episode of neck pain typically have rapid improvement in symptoms: an observational study. J Physiother 2013;59:31-7.

44. Childs JD, Fritz JM, Wu SS, et al. Implications of early and guideline adherent physical therapy for low back pain on utilization and costs. BMC Health Serv Res 2015;15:150.

45. Spitzer WO, Skovron ML, Salmi LR, et al. Scientific monograph of the Quebec Task Force on Whiplash-Associated Disorders: redefining "whiplash" and its management. Spine 1995;20(8 Suppl):1S-73S. 